\title{
Non-Cytotoxic Chemotherapy
}

National Cancer Institute

\section{Source}

National Cancer Institute. Non-Cytotoxic Chemotherapy. NCI Thesaurus. Code C118620.

Chemotherapy using a pharmacologic agent that does not directly kill cells. 